\title{
The Sedimentary Facies and Evolution Characteristics of the Middle and Deep Strata in the Nanpu No. 3 Structural Area
}

\author{
Hui Zhang *, Zhiqin Lan, Xiaoyan Li and Xinglong Huang \\ Shandong Institute of Coal Geology Planning and Exploration, Jinan, China
}

In this study, due to the inconsistencies in the understanding of the sedimentary types in the second section of the Dongying Formation $\left(\mathrm{Ed}_{2}\right)$ and the third section of the Shahejie Formation $\left(\mathrm{Es}_{3}\right)$ in the middle and deep strata of Nanpu No. 3 structural area, the depositional characteristics of the deep braided river delta, fan delta, deep-water slump turbidite fan, and coastal and shallow lake in the Nanpu No. 3 structural area

OPEN ACCESS

Edited by:

Dawei Lv,

Shandong University of Science and

Technology, China

Reviewed by:

Xianfeng Tan,

Chongqing University of Science and Technology, China

Pengwei Wang,

SINOPEC Petroleum Exploration and Production Research Institute, China

*Correspondence:

Hui Zhang

22207536@qq.com

Specialty section:

This article was submitted to

Sedimentology, Stratigraphy and

Diagenesis,

a section of the journal

Frontiers in Earth Science

Received: 30 April 2021

Accepted: 16 June 2021

Published: 30 June 2021

Citation:

Zhang H, Lan Z, Li $X$ and Huang $X$

(2021) The Sedimentary Facies and

Evolution Characteristics of the Middle and Deep Strata in the Nanpu No. 3

Structural Area.

Front. Earth Sci. 9:703070.

doi: 10.3389/feart.2021.703070 were examined in-depth. The investigations were begun based on the descriptions and observations of core samples obtained from eight cored wells in the study area, in combination with seismic, well logging, and rock ore data. The results revealed that the sources of the material in the study area originated from the Shaleitian salient in the southwest direction. It was determined that the fan deltas and the shallow lake sedimentary system had developed during the SQ1 sequence and SQ2 sequence periods. The braided river deltas and the shallow lake and turbidite sedimentary system with multi-stage superposition had developed during the SQ3 to SQ7 sequence periods, and their distribution range had been controlled by the structural background of the gentle slope zone of the lake basin. On that basis, a sequence deposition filling model controlled by a slope break zone in the middle and deep strata of the Nanpu No. 3 structural area was established in this study starting from the typical seismic profile, in which such factors as the tectonic activity characteristics, lake basin boundary shape, water depths, and so on, were comprehensively considered. The goal of this research investigation was to provide beneficial information for oil and gas explorations in similar areas.

Keywords: Nanpu No 3 structural area, sedimentary facies, sedimentary evolution, slope break zone, Braided river delta

\section{INTRODUCTION}

The Nanpu Sag is a type of Mesozoic-Cenozoic superimposed compound sag located in the northern section of the Huanghua Depression in the Bohai Bay Basin. The Nanpu Sag displays the active rift characteristics of polyphase extensions and inheritance development which occurred during the Mesozoic and Cenozoic Periods (Qi et al., 2010; Ran et al., 2010). Since oil and gas explorations in the Nanpu No. 3 structural area began, industrial oil flow has been found in the Paleogene Shahejie Formation. In August of 2014, a breakthrough discovery was made in the Dongying Formation. The 


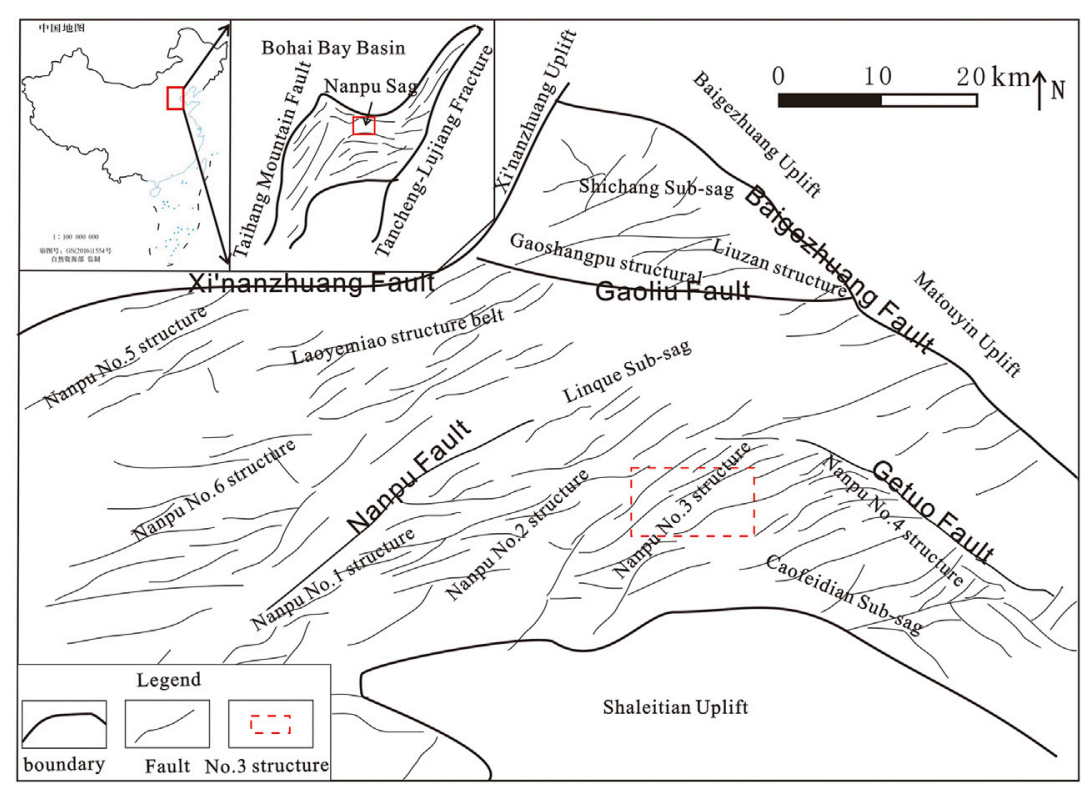

FIGURE 1 | Structural location diagram of the Nanpu No. 3 structural area.

daily oil production of the Nanpu $306 \times 9$ well was $7.679 \mathrm{~m}^{3}$ during the oil production tests. A series of new discoveries showed that the No. 3 structural area was an important oil and gas exploration target and replacement position in the Nanpu Sag. In recent years, some researchers have studied the middle and deep strata of the Nanpu No. 3 structural area. The previous studies mainly focused on the characterization analyses of sedimentary sand bodies and the reservoir characteristics in the first section of the Shahejie Formation and the third section of the Dongying Formation (Xu, 2006; Feng et al., 2010; Huang et al., 2012; Jiang et al., 2013; Dong et al., 2014; Jiang et al., 2018; Wang et al., 2019; Wu et al., 2019). Previous research on the source direction of the Nanpu No. 3 structure has not been unified, and it is believed that it may have originated from the uplift plate of the Bogezhuang fault, the uplift plate of the Gaoliu fault, the Shalietian uplift, and the Shiyutuo uplift (Xian et al., 2012; Liu et al., 2017). Most scholars agree that in the Nanpu Sag the fan delta is developed in the steep slope zone, braided river delta in gentle slope zone and slump turbidite fan (Li et al., 2018; Wang et al., 2020; Sun et al., 2021). The slope break zone is an important concept formed on the basis of studying the sedimentology and sequence stratigraphy of marine sedimentary basins. This term refers to the zone where the topographic slope changes. More and more examples of oil and gas exploration show that there are slope break zones present in both of the continental basins, which clearly control the distribution of the overlying strata, lithology and lithofacies and the distribution of oil and gas reservoirs (Lin et al., 2000; Wang et al., 2002; Li et al., 2008). However, at the present time, there is a lack of in-depth research regarding the sedimentary facies and sedimentary filling processes of the middle and deep strata. In the current investigation, the main sedimentary facies and sedimentary evolution characteristics of the Nanpu No. 3 structural area were systematically examined in accordance with the observations and descriptions of $168 \mathrm{~m}$ cores taken from 14 cored wells in Nanpu No. 3 structural area, in combination with the seismic data, logging data, and testing data. In addition, such factors as the tectonic activity characteristics, boundary fault morphology, climate conditions, water depth, and so on, were comprehensively considered. Then, taking the Nanpu No. 3 structural area as a prototype, a sedimentary filling model controlled by a slope break zone was established in order to provide a basis for searching for favorable reservoir sand bodies with potential for further evaluations.

\section{GEOLOGIC SETTING}

The Nanpu No. 3 structure is located in the southeastern section of the Nanpu Sag, which is situated in the northern region of the Huanghua Depression in the Bohai Bay Basin. The Nanpu No. 3 structure is adjacent to the Nanpu No. 4 structure in the east; Nanpu No. 2 structure in the west; Shaleitian Salient and Caofeidian Sub Sag in the south; and the Linque Sub Sag in the north (Zhou et al., 2000; Jiang et al., 2009; Fan et al., 2010; Li et al., 2011) (Figure 1). It is essentially an uplift area between the two sub sags, with a structural area of approximately $240 \mathrm{~km}^{2}$. Its overall structural pattern is that of an east-west spreading, and the secondary faults mainly trend in a NE direction. The Nanpu No. 3 structural area is a fault anticline structure developed on a Cambrian buried hill, which is characterized by the Paleogene Shahejie formation, Dongying Formation, Neogene Guantao Formation, Minghuazhen Formation, and a quaternary plain formation in turn above it. This is also a lack of Paleozoic to Mesozoic strata in the area. According to the characteristics of sequence boundaries, the Paleogene in the Nanpu No. 3 structural area can be divided into three second-order sequences and eight 


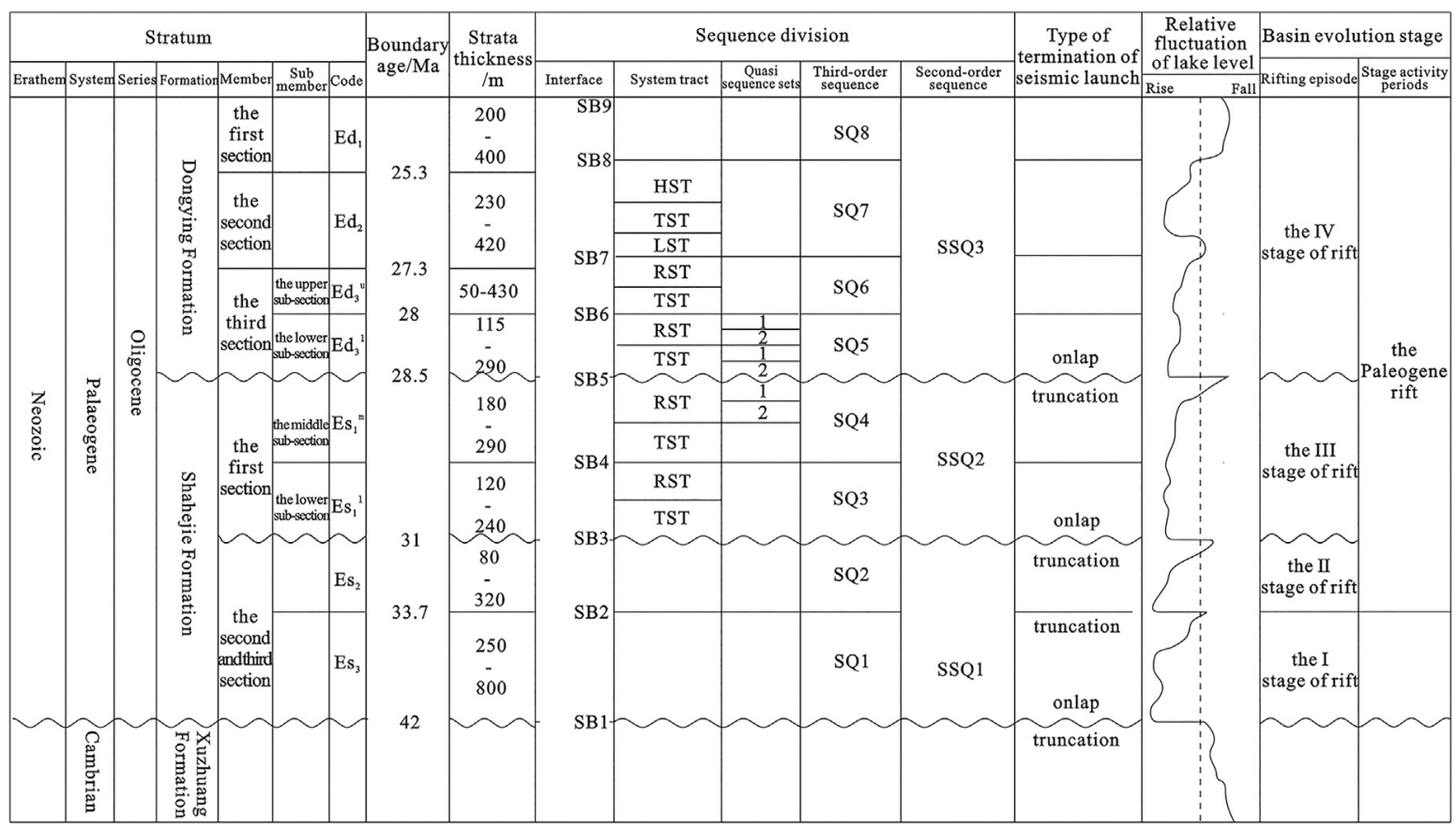

FIGURE 2 | Division and correlation of the Paleogene sequence stratigraphy and lithostratigraphy in the Nanpu No. 3 structural area.

third-order sequences using the stratigraphic division scheme of strata (for example, SQ1 to SQ8). The system tracts of each sequence can also be subdivided, as shown in Figure 2. The middle and deep strata in the study area include the second section of the Dongying Formation $\left(\mathrm{Ed}_{2}\right)$ and the third section of the Shahejie Formation $\left(\mathrm{Es}_{3}\right)$, referred to in this study as SQ1 to SQ7.

\section{SAMPLES AND METHODS}

The observations and descriptions of $168 \mathrm{~m}$ cores in 14 coring Wells in the Nanpu No. 3 structural area were carried out, and 10 rock ore analyses were completed. At the same time, the data of drilling, logging, testing and seismic data of 32 wells in the middle and deep depths of the study area were collected from oil field companies for reprocessing, interpretation and research analysis. In this study, the middle and deep layers of the Nanpu No. 3 structure were taken as the research object, and the second member of Dongying Formation to the first member of Shahejie Formation was taken as the key research section. Next, the sequence stratigraphy and sedimentology were studied, the provenance direction was clarified, and the sedimentary characteristics and filling mode of the gentle slope zone in the study area were analyzed.

\section{RESULTS}

\section{Source Directions}

The southern margin of the Nanpu No. 3 structural area is located close to the Shaleitian Salient area, and structurally belongs to the northern slope of the Shaleitian Salient. The rock composition characteristics of the first section of the Shahejie Formation in the study area include light mineral quartz content $(<50 \%)$ and feldspar (content of 25-50\%), which belong to arkose and lithic arkose (Figure 3A). The heavy minerals in the area mainly include zircon, pyrite, and anatase (Figure 3B). According to the plane distribution trend of the light mineral content, the relative quartz content generally increases from the southwest to the northeast. It is believed that the material sources of the Nanpu No. 3 structural area mainly originate from the Shaleitian Salient area in the southwestern direction (Figure 3C), and the material source openings are distributed in the developmental parts of the main fault in the north-eastern direction. The material sources were injected along the trough fault formed by the NE-trending faults. During the advancement processes from the edges of the gentle slope to the lake basin along the material source direction, the grain sizes of the sediment became finer; degrees of sorting and grinding became higher; composition maturity increased; and the argillaceous content levels in the lake basin area increased significantly, while the relative sand content significantly decreased. 


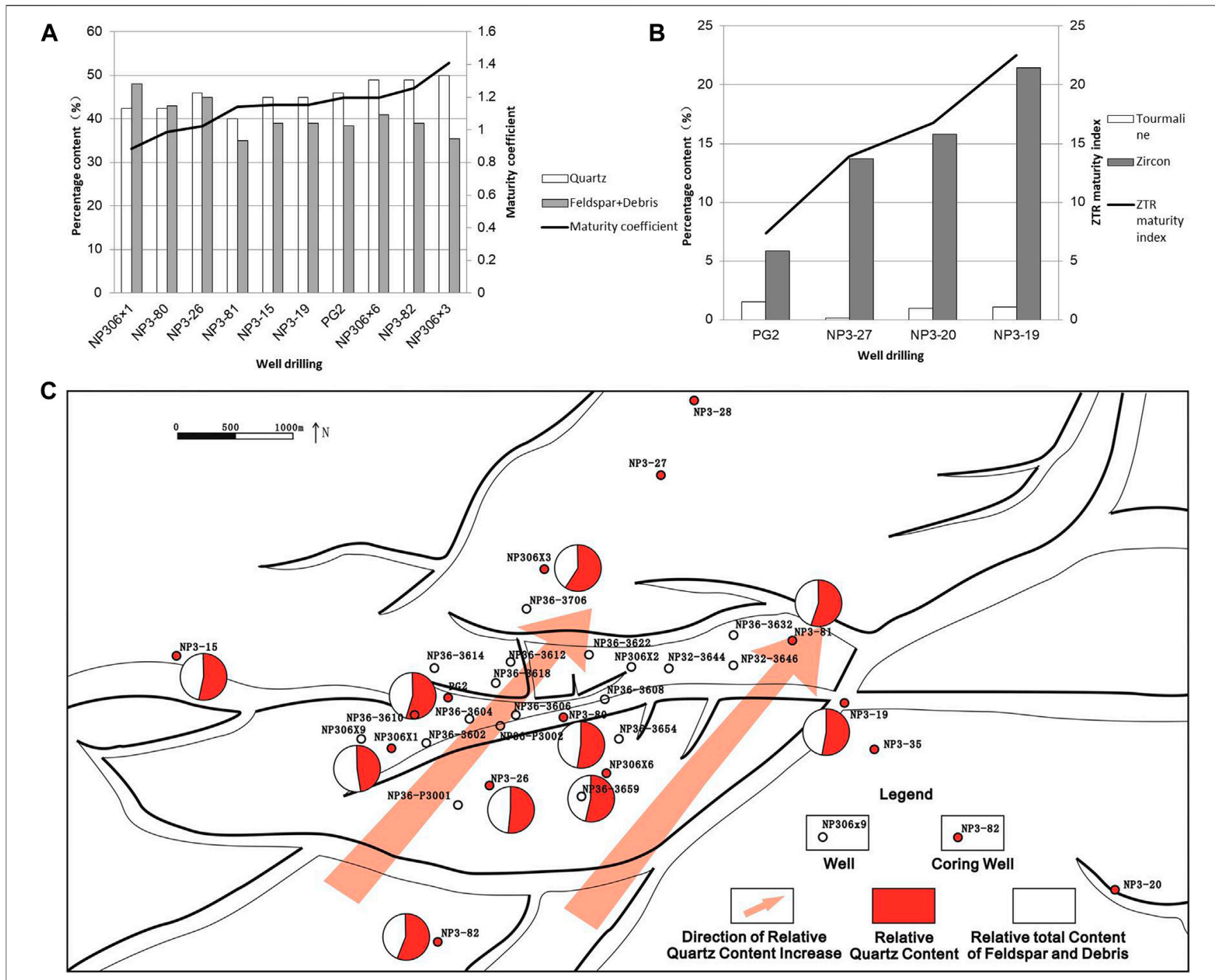

FIGURE 3 |Analysis results of material source directions in the middle and deep strata of the Nanpu No. 3 structural area. (A) Histogram of light mineral content of rock in different well areas; (B) Histogram of heavy mineral content of rock in different well areas; (C) Distribution trend of light mineral content in rocks of Nanpu No. 3 structural area.

\section{Types and Characteristics of the Sedimentary Facies Braided River Delta}

When the braided river carried large amounts of terrigenous sediment into the lake after long-term transportation processes, the sediment carried by the braided river rapidly accumulated at the mouth of the lake due to the decreases in the braided river's velocity. As a result, tongue-shaped, fan-shaped, or lobate sedimentary complexes were formed on the plane and wedgeshaped sedimentary complexes were formed on the section (e.g. the braided river delta deposits) (Liu et al., 2015). The braided river delta deposits in the Nanpu No. 3 structural area were developed in each system tract of the SQ3 to SQ8 sequence. There were observed to be mainly located in the lacustrine regression tract, and the high-stand tract and low-stand tract of each sequence and were apparent in the central and southern plane sections of the study area. In addition, there were deposits of dark gray mudstone, argillaceous siltstone, and sandstone interbedding mixed with small amounts of fine sandstone and glutenite. In term of the sedimentary tectonics, these were found to be dominated by parallel bedding, oblique bedding, and plate cross-bedding, and with scour filling structures located at the bottom. The Nanpu No. 3 structural area was observed to be dominated by braided delta front sub-facies with limited sedimentary range, which further identified in the underwater distributary bay, main body of the underwater distributary channel, estuary dam, and the lateral edges of the underwater distributary channel. 

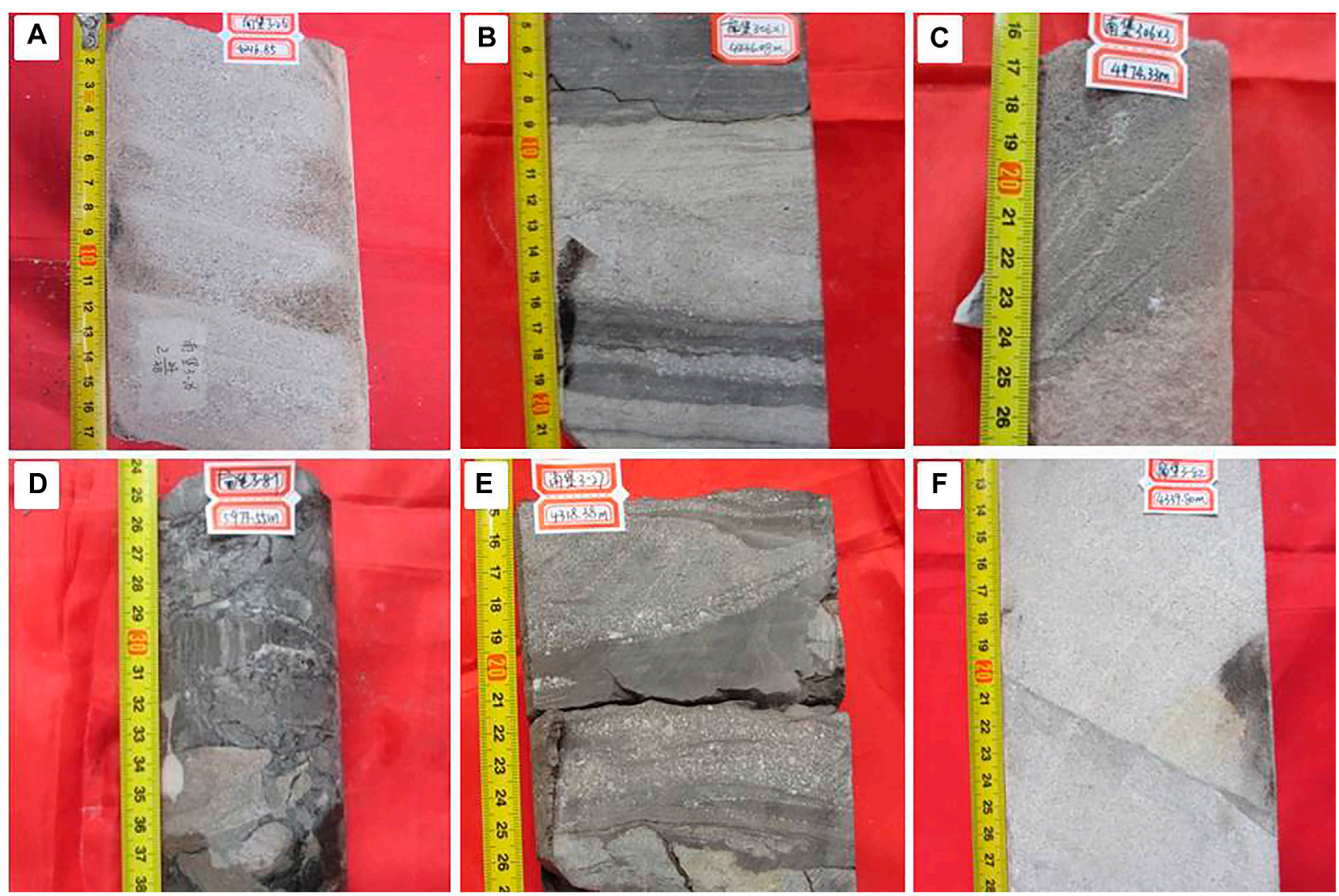

FIGURE 4 | Lithofacies marks of the middle and deep layers in the Nanpu No. 3 structural area: (A) NP3-26 (4,216.85 m), positive rhythm coarse sandstone gravel in the main body of underwater distributary channel in the braided river delta front; (B) NP306 $\times 1$ (4,236.08 m), greyish black gravelly mudstone and grayish white sandstone in the underwater distributary bay of the braided river delta front; (C) NP306 $\times 3$ (4974.33 m), grey medium sandstone of estuary dam in the braided river delta front; (D) NP3-81 (5,973.55 m), grey black mudstone interbedded with gravel in the braided river delta front; (E) NP3-27 (4,318.94 m) deep-water slump turbidite fan with mudstone bands in the grey pebbled sandstone of the agitated structure; (F) NP3-82 (4,339.8 m), grayish white medium sandstone of the beach bar.

\section{Main Body of the Underwater Distributary Channel}

The lithology of the study was mainly composed of gravelly sandstone and fine sandstone, and presented multiple sets of vertically positive rhythm with typical structures, such as bottom scouring and oblique bedding (Figure 4A) and significant progradational reflection characteristics. These features were widely developed and distributed in each sequence of the study area, displaying good physical properties associated with reservoirs and oil-bearing reservoirs. The grain sizes were observed to be coarse in the lower parts and fine in the upper parts. In addition, the logging curve amplitude was determined to be medium to high, and characterized by thick layer bell shapes, box shapes, and bell-box combined shapes. The natural gamma ray curves revealed toothed box shapes (Figure 5A). In the vertical direction, the area transitioned from multi-stage pebbled gray stone and sandstone to fine sandstone and siltstone, and the bottom scouring structure was considered to be common.

\section{Side Edge of the Underwater Distributary Channels}

The underwater distributary channel in front of the braided river was further subdivided and generally located at the edges or lateral edges of the distributary channels. These were found to have similar sedimentary characteristics as the subaqueous distributary channels but were characterized with finer rock granularity.

\section{Underwater Distributary Bays}

The underwater distributary bays were located in relatively lowlying areas between the underwater distributary channels and had small distribution areas within the study area. Therefore, they were considered to not have the conditions suitable for oil storage. The cores were dominated by mudstone and silty mudstone (Figure 4B). In terms of the logging responses, the natural gamma logging curves and resistivity logging curves displayed low amplitude tooth shapes (Figure 5B). 


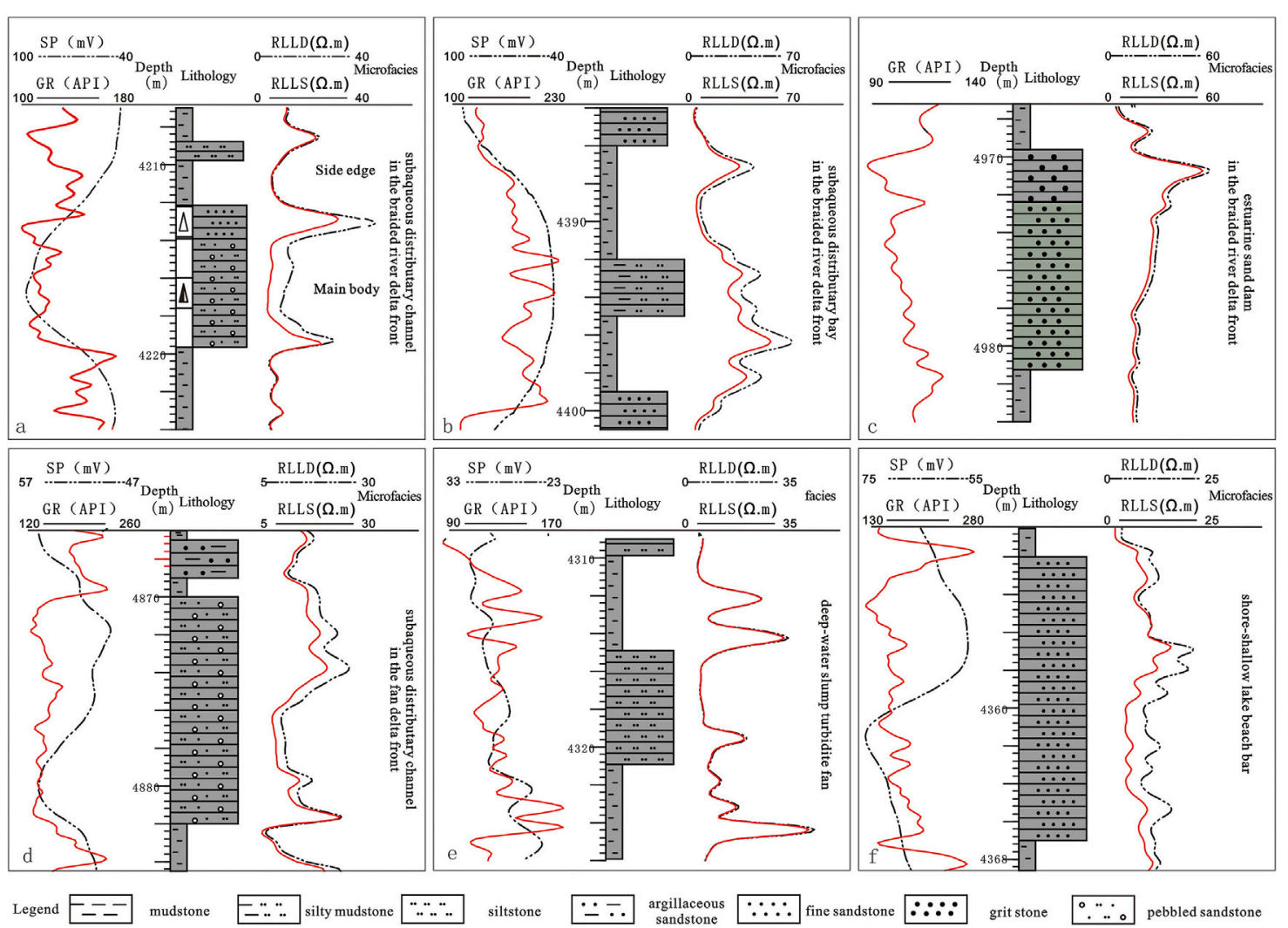

FIGURE 5 | Lithologic assemblage and logging response characteristics of the different sedimentary facies in the middle and deep layers of the Nanpu No. 3 structural area. (A) NP3-26, SQ4; (B) PG2, SQ4; (C) NP306 × 3, SQ4; (D) NP3-82, SQ2; (E) NP3-27, SQ5; (F) NP3-82, SQ4.

\section{Estuarine Sand Dams}

In the front section of the underwater distributary channels, estuarine sand dams were observed to have formed at the entrances of the estuaries emptying into the lakes. These were generally oval in shape, with long axis advances along the river direction to the lake basin. The lithology was determined to be composed of medium and fine-grained sandstone (Figure 4C), with high maturity in composition and structure. In addition, in the vertical direction, the lithology was characterized by inverse grain sequences, and the logging curves were funnel-shaped (Figure 5C). These features were only developed on a small scale in the NP306 $\times$ 3 section. However, in other well areas in the northern part of the study area, they were found to be mainly developed as massive bedding, small cross-bedding, and parallel bedding formations.

\section{Fan Deltas}

Fan deltas are fan-shaped or cone-shaped sedimentary bodies (Jiao et al., 1998; Liu et al., 2008; Zhang et al., 2015) which are formed by the rapid accumulation of alluvial fans when they enter a lake or sea. These are one of the important genetic types of reservoirs in the Shahejie Formation within the Nanpu No. 3 structural area. The fan deltas are mainly distributed in the southern section of the study area. In the southwestern and northeastern sections, the fan deltas are mainly wedge-shaped, and in the northwestern and southeastern sections, they are mainly mound-shaped. The development of fan deltas is affected by the backgrounds of the lake basins, material source supplies, and tectonic activities. Steep slope zones are considered to be more favorable to fan delta formation. In the study area, fandelta front sub-facies were observed to be developed. These were mainly composed of coarse-grained clastic deposits characterized by coarse granularity and small distributions.

The fan delta fronts were mainly developed during the sedimentary periods of the SQ1 and SQ2, and the lithology is mainly conglomerate, glutenite, and massive mudstone deposits (Figure 4D). The content of conglomerate has been found to be relatively high, and the gravel composition is primarily calcareous and argillaceous, showing obvious contrast with the braided river delta fronts. The logging curves indicate a combination of toothed bell types and toothed box types (Figure 5D), and the seismic event axis display the characteristics of high frequency progradation or random reflection.

\section{Deep-Water Slump Turbidite Fans}

In the current study, sedimentary sand bodies of different scales and limited distributions were found to be developed in the lacustrine sedimentary area of the Nanpu No. 3 structural area. These were observed to be rich in sedimentary structure types, such as scour surfaces, oblique bedding, undulated bedding, and the directional alignment of grains. They were found in the 
NP306 $\times 1$ well, NP306 $\times 6$ well, NP3-81 well, and so on, which reflected the dynamic characteristics of traction water. Some cored intervals (such as the PG2 well $(3,632.7 \mathrm{~m}$ ) and the NP3-27 well $(4,137.75 \mathrm{~m})$ displayed the phenomena of agitation deformations and trough membrane, which represented the characteristics of gravity flow deposition. In addition, from a lithological perspective, mainly mudstone intercalated with siltstone was observed, with obvious agitation deformation structures (Figure 4E). The logging curves were bellshaped with low amplitude teeth (Figure 5E), and the seismic reflection events mainly showed wavy or random reflection characteristics.

The deep-water slump turbidite fan sand bodies in the Nanpu No. 3 structural area were determined to be distributed in each system tract of the SQ3 to SQ8 period, and were commonly found in the low-stand tract and the lake regression areas. They were considered to have been formed by the slumping effects of the fan deltas and braided river delta front sand bodies toward the center of the lake basin. These types of sand bodies are known to easily form into lithologic reservoirs. However, they can also develop into self-generating and self-preserving reservoirs with source rock.

\section{Shore-Shallow Lakes}

When compared with other sedimentary microfacies, shoreshallow lakes are characterized by finer grain sizes, darker coloration, and higher organic matter content. The rock types are mainly composed of claystone and siltstone with welldeveloped horizontal bedding, and belong to the categories of weak reducing or reducing environments. The lithology is generally stable horizontally, and mainly composed of dark grey mudstone with horizontal bedding, which is controlled by the structural slope break zone. There may also occasionally be mixtures of massive fine sand and siltstone of slump turbidite origin.

The beach bars of shore-shallow lakes could be seen locally in the study area, and were particularly developed in the NP3-82 well at the edge of the lake basin. The lithology was observed to be composed of pure medium-fine sandstone with gray coloration (Figure 4F). The composition maturity and structural maturity were found to be high, and the logging curves were smooth funnel-shaped or symmetrical (Figure 5F).

\section{Sedimentary Evolution Characteristics}

The sand-bodies located in the middle and deep strata of the Nanpu No. 3 structural area were found to have the characteristics of inheritability and variability during each period. Overall, the distribution characteristics of the sand bodies (from old to new) in the study area from the SQ1 sedimentary period to the SQ7 sedimentary period were as follows: The channel sand bodies were controlled by the sedimentary conditions, and were mainly distributed in strips and sheets on the plane; the estuary sand dams and shore-shallow lake beach dams were distributed in elliptical shapes, potato shapes, or irregular shapes sat the ends of the underwater distributary channels; the lateral edges of the underwater distributary channels were distributed in strips and sheet shapes along the sides of the main channel body; the slump turbidite bodies were mainly distributed irregularly at the boundaries of or outside the channel sand bodies, and the distribution ranges had differed during the different periods; the study area presented the characteristics of a sedimentary assemblage composed of fan deltas, shore-shallow lakes or braided river delta fronts, and shore-shallow lakes and turbidite, with the sand bodies displaying good connectivity.

\section{Sedimentary Evolution Characteristics of the SQ1 and SQ2 Sequences}

SQ1 and SQ2 sequences are the initial development stages of the second-order sequence of the Shahejie Formation, which correspond to the third and second section of the Shahejie Formation, respectively. The gentle slope zone in the Nanpu No. 3 structural area developed thick proximal fan delta deposits due to the intense activities of the northern Shahejie Fault in the southwest. In addition, fan delta front deposits can be seen in the western well area of the region, but the distribution is relatively limited. Those deposits are mainly composed of the main body of the underwater distributary channels, side edges of the underwater distributary channels, and the inter-distributary bays in the fan delta fronts. In the plane areas, two lobes have developed in the fan delta fronts which advance toward the lake basin. The first lobe includes the main underwater distributary channel which is distributed along the NP3-82, NP32-3646, and NP3-81 wells in a strip shape. The other lobe is the advancing direction of the fan delta front close to the eastern section of the study area. Its scale is smaller than that of the delta front in the west, and its underwater distributary channel advances toward the NP3-20 well (Figure 6A). During the periods of sequences SQ1 and SQ2, the lacustrine sediment in the study area were widely distributed. SQ1 and SQ2 are considered to be the two complete water transgression-regression cyclic sedimentation sequences which correspond to the Stage I and Stage II activity periods of the Paleogene rifts in the Nanpu No. 3 structural area.

\section{SQ3 Sedimentary Evolution Characteristics}

The SQ3 sequence was formed during Stage III of the rifts in the Nanpu Sag, which roughly corresponds to the lower subsection of the Shahejie Formation 1. The lake water in the Nanpu No. 3 structural area began to regress during that period, and could be divided into a transgressive system tract and a regressive system tract. The rock characteristics of the study area from the SQ3 sequence period were observed to be obviously different from those of the SQ1 and SQ2 sequence periods. For example, they were mainly composed of fine-grained sandstone and sand mudstone, with small amounts of magmatic rock observed in local areas. It has been considered that braided river deltas and lacustrine facies were probably dominant during the period. It has been determined that braided river delta front-shore shallow lake depositional systems were developed during the lake transgression tract period, evidenced by the two braided river delta fans in the eastern and western sections of the study area. The Idistribution ranges of the braided river delta fronts were small (Figure 6B), and the water bodies experienced temporary expansions within a small range. In the vertical direction, the area was mainly composed of retrograding parasequence formations, in which the lower single sand layers 


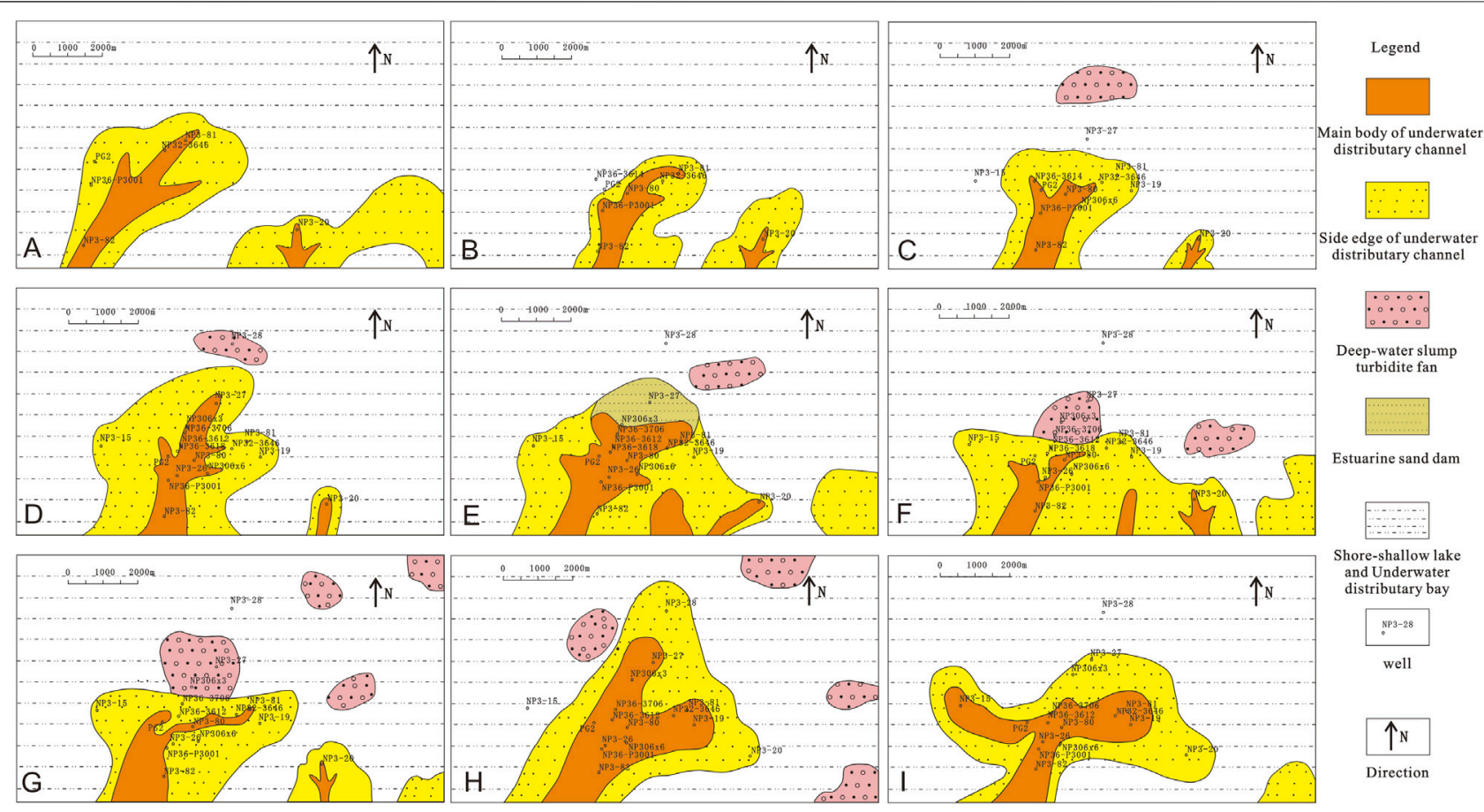

FIGURE 6 | Sedimentary microfacies of SQ1 to SQ7 system tracts in the Nanpu No. 3 structural area. (A) Sedimentary microfacies of SQ1 and SQ2; (B) Sedimentary microfacies of SQ3 transgressive system tract; (C) Sedimentary microfacies of SQ3 regressive system tract; (D) Sedimentary microfacies of SQ4 transgressive system tract; (E) Sedimentary microfacies of SQ4 regressive system tract; (F) Sedimentary microfacies of SQ5 transgressive system tract; (G) Sedimentary microfacies of SQ5 regressive system tract; (H) Sedimentary microfacies of SQ7 lowstand system tract; (I) Sedimentary microfacies of SQ7 highstand system tract.

were thick; upward sand bodies were relatively thin; and the amount of upper mudstone had increased, particularly in the well area. Generally speaking, the lake regression tract indicated that the braided river deltas continued to advance into the lake basin, and a depositional system of braided river delta fronts with shallow-shore lake and turbidite was dominant. In addition, when compared with the lacustrine transgression stage, the lobe bodies of the braided river deltas had gradually become larger and the underwater distributary channels became wider during the lacustrine retrogression stage. As a result, along the advancing direction of the braided river deltas, potato-shaped deep-water slump turbidite sand bodies had developed (Figure 6C). This study found that the majority of the wells in the study area (for example, the PG2 well, NP3-80 well, and so on) exhibited progradation para-sequence formations in the vertical direction. It could be observed that the content levels of sandstone increased upward, while the content levels of mudstone were lower with reduced thicknesses, indicating that there had been a temporary water regression in the lacustrine regressive system tract.

\section{SQ4 Sedimentary Evolution Characteristics}

The SQ4 roughly corresponded to the middle subsection of the Shahejie Formation 1, which had formed during the late period of the Stage III rifts in the Nanpu Sag. The water areas in the study area showed continuous water regression had occurred. After the
SQ4 period, the study area was uplifted as a whole. Meanwhile, the entire upper subsection of the Shahejie Formation 1 was denudated. The SQ4 sequence can be divided into a lacustrine transgressive system tract and a lacustrine regressive system tract where the braided river delta fronts and deep-water slump turbidite deposits can be seen to have developed. Its plane distribution range was obviously larger than that of the SQ3 sequence system tract. During the SQ4 sequence period, the braided river deltas advanced forward to the lake basin, and the braided river delta front deposition was the most developed. However, the main channel was also very prominent. This study observed that, along the southwestern direction of the material sources, delta fronts had formed and been distributed toward the lake basin (Figures 6D,E). The underwater distributary channels were the main part of the deposition during that period, and estuary dam deposits had become well developed in the channel fronts. The drilling data revealed that a large set of argillaceous deposits in the underwater distributary bays were also developed in the lateral margin, and potato-shaped beach dam sand bodies were scattered in parts of para-sequence 1 . The deep-water slump turbidites were found to have been mainly distributed in the northeastern section. Underwater channel deposits with large sand thicknesses were encountered during the drilling processes of well NP36-3618, well NP3-26, well NP36-3612, and well NP363706. In addition, estuary dam microfacies were encountered during the drilling of wells NP306 $\times 3$ and NP3-27 in the northeastern margin, and beach dam microfacies were 
encountered during the drilling of well NP3-82 near the central and southern margins. As the study area was relatively small, the lobate shapes of the braided river delta fronts were the only local shape observed.

\section{SQ5 Sedimentary Evolution Characteristics}

Following the tectonic uplifts which occurred in the late sedimentary period of the Shahejie Formation, the Nanpu No. 3 structural area was denuded as a whole and entered Stage IV of the rift activity period. During the early stage, SQ5 was formed by sedimentary filling action, which roughly corresponds to the third eastern subsection. During that period, the lake basin had strongly expanded and presented a trend of transgression, which could be divided into a lacustrine transgressive system tract and a lacustrine regressive system tract. Each system tract could then be subdivided into two para-sequence formations. The braided river delta front-shallow shore lake-deep-water slump turbidite deposits had mainly accumulated during the period of the SQ5 lacustrine transgressive system tract. During that time period, the sedimentary sand bodies in the underwater distributary channels of the braided river delta fronts were reduced, and the water channels became narrower and smaller. Those channels were mainly distributed in the area of the NP306 $\times 1$ and NP3-80 wells. The argillaceous sediment in shallow shore lakes increased, indicating that the depths of the water bodies had increased to a certain extent. In the northern section, deep-water slump turbidite deposits of semi-deep and deep lakes were evident, with the number of turbidite sand bodies continuously increasing from the bottom to the top. In addition, from the middle section to the northeastern section, it was observed that the turbidite sand bodies were mainly potatoshaped and irregular due to the smaller range of the turbidite sand bodies in the direction of the material sources (Figure 6F). During the lacustrine regression system tract period of the SQ5, the sedimentary system and lacustrine transgressive system tracts displayed the characteristics of inheritance. On the whole, the braided river deltas were still in the form of retrogradation, and the deep-water slump turbidite sand bodies were smaller (Figure 6G). In summary, the lake basin area had strongly expanded during the early stage of the Dongying Formation, and the delta lobes regressed as a whole during the SQ5 period. Moreover, the scale of the lobes was small, and the channels had become narrower with poor continuity. A large number of slump turbidite deposits were formed in front of the deltas under the influencing effects of the tectonic activities.

\section{Sedimentary Evolution Characteristics of SQ6 and SQ7}

A lacustrine transgressive system tract and a lacustrine regressive system tract were developed during the SQ6 sequence period, and that period was a period of structural transformation. The strata in the Nanpu No. 3 structural area were seriously faulted, especially in the middle fault block area. The braided river delta front and shallow shore lake depositional systems were mainly developed during the SQ6 sequence period. However, when compared with the SQ5 sequence period, the depositional range of the braided river delta fronts was reduced, while the lake basin range was enlarged.

The low stand tract, lacustrine transgressive system tract and high stand tract were developed during the SQ7 sequence period. During that period, the tectonic activities were generally stable and the material sources were sufficient. In addition, the braided river delta areas also had larger scales overall. The underwater distributary channels were significantly larger in scale than during the SQ5 and SQ6 sequence periods and had migrated to the northeast. The lake areas had also regressed to the northeast, and the scope was smaller than during the SQ5 and SQ6 sequence periods, as illustrated in Figures 6H,I.

\section{Sedimentary Filling Mode}

The sequence stratigraphic characteristics, system tract composition and sedimentary system were analyzed in detail, and the control factors of the Nanpu No. 3 structural sequence development were taken as the starting points in the present study. Then, based on the comprehensive study of the types and characteristics of the sequence boundaries; division of the sequence boundaries at all levels; determination of the sequence division scheme; and the establishment of the isochronal sequence stratigraphic framework suitable for the study area, such factors as the tectonic activities, lake basin form, and so on were highlighted. Subsequently, in accordance with the interpretations of the typical seismic sections and some three-dimensional seismic sections in the Nanpu No. 3 structural area, this study's sequence stratigraphic models of the area could be summarized as the following two types: (1) A sequence sedimentary filling model without a slope break zone; and (2) A sequence sedimentary filling model with a slope break zone (Ren et al., 2004; Xu et al., 2006; Li et al., 2010; Lv et al., 2019; Lv et al., 2020).

\section{Sequence Sedimentary Filling Model Without a Slope Break Zone}

The SQ1 to SQ6 developmental periods in the Nanpu No. 3 structural area were characterized by asymmetric faulted lacustrine basin deposits. Therefore, it was considered that that type of sequence filling model was the most important sedimentary filling model in the study area. The model lacked a slope break zone in its structural design style. It was divided into a lacustrine transgression system tract and a lacustrine regressive system tract due to the difficulty in determining the initial flood surfaces in the system tract composition. During the development of that particular sequence model, the subsidence and sedimentary centers of the lake basin were located in the northeastern section of the study area, and multiple faults were developed in the gentle slope areas, which were considered to be basically normal faults. The most important fault was the No. 3 fault (Zhang and Liu, 2012; Zhou et al., 2016). In the gentle slope zone of the Nanpu No. 3 structural area, the material sources originated from the Shalietian Salient in the southwestern direction. On the seismic profile, each sequence showed wedge-shaped bodies overlapping to the shore, with small overall thicknesses but long extension distances. The sedimentary system was mainly composed of alluvial fans, braided river deltas, shallow-shore 


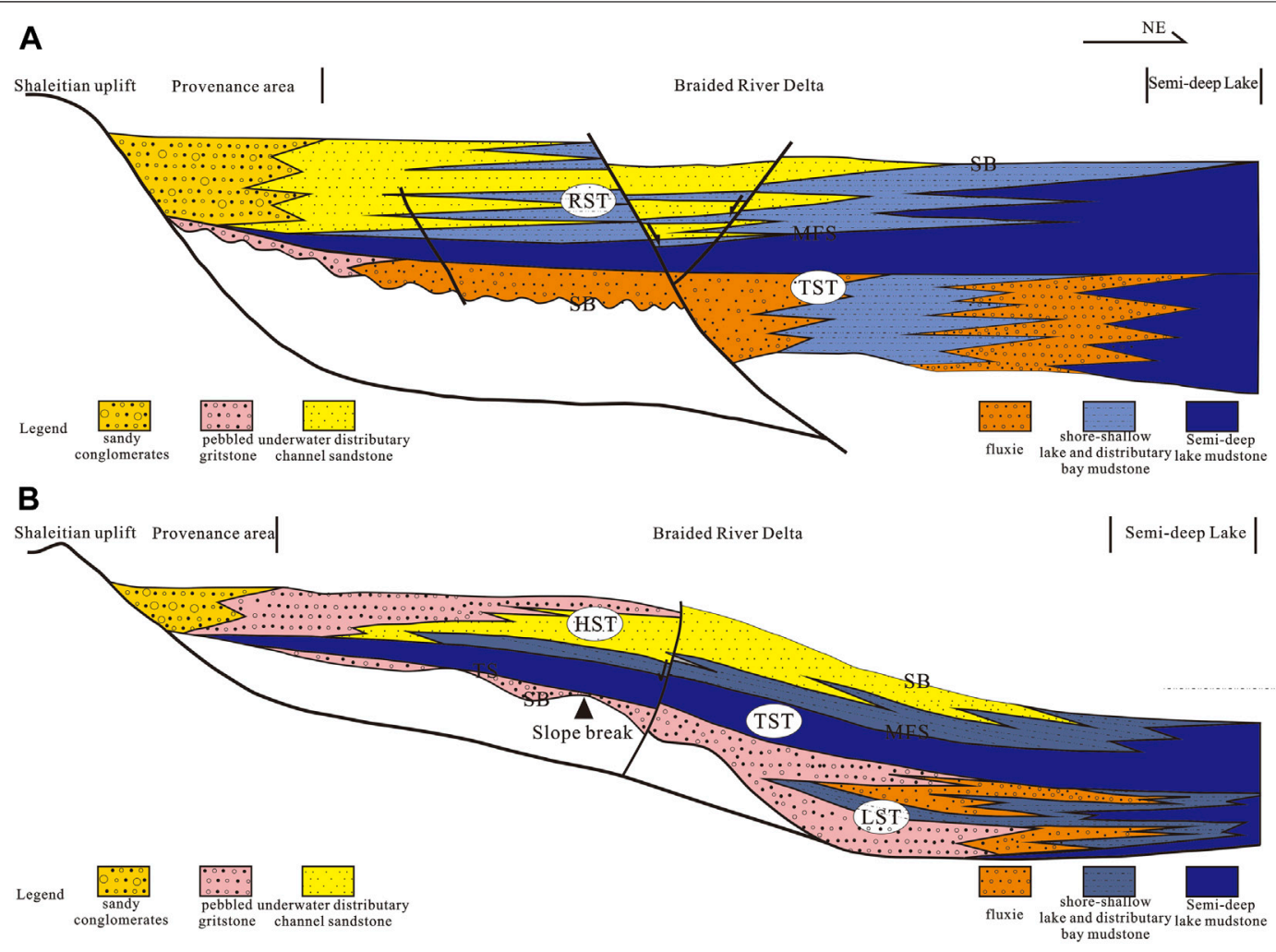

FIGURE 7 | Sedimentary filling model of the middle and deep strata in the Nanpu No. 3 structural area. (A) Sequence sedimentary filling model without slope break zone (SW to NE); (B) Sequence sedimentary filling model with slope break zone (SW to NE).

lakes, and semi-deep lakes. Some of the sequences (for example, SQ1 and SQ2) had developed fan deltas instead of braided river deltas.

In the present research investigation, the SQ4 sequence period was taken as the object in order to establish the sequence of the gentle slope zones without slope break zones. Its system tract development model is detailed in Figure 7A. This model sequence was internally divided into a lacustrine transgressive system tract and a lacustrine regressive system tract, and the sedimentary characteristics of each system tract were significantly different. For example, at the bottom of the lacustrine transgressive system tract (TST), small braided-river delta front sand bodies were developed. At the lower part, there were mudstone deposits of shallow shore lakes. In addition, slump turbidite deposits with mixed particles in a limited distribution range appeared and a transition to semi-deep lacustrine facies occurred. After that, the lake level began to rise, and the scope of the lake basin expanded, resulting in the beginning of a large-scaled lake transgression. At that time, the growth rate of the accommodation spaces was greater than the sediment supply rate. In the Nanpu No. 3 structural area, the large-scale deposition of the lacustrine facies had been dominated by dark mudstone. Then, after the lake basin reached its maximum range, the lake level began to decline, which indicated that the area had entered into a lacustrine regressive system tract (RST) period. During the early stages of the lacustrine regressive system tract, the main body was stable. The supply of deposits was small during that period and shallow-shore lake deposits had developed. Subsequently, the accommodation spaces became decreased. However, with the increases of the sediment supplies, a series of large-scaled braided river deltas were gradually formed, which advanced toward the lacustrine basin displaying a series of progradation characteristics.

\section{Sequence Sedimentary Filling Model With a Slope Break Zone}

This type of sequence filling pattern mainly appeared during the SQ7 sequence period when a tectonic slope break zone had appeared due to tectonic actions. The occurrence of this structural slope break zone had a controlling effect on the formations of the low water level system tract and the sequence boundaries. For example, when the lake level had not exceeded the slope break zone, the area above the slope break zone entered a state of weathering and denudation, and unconformity surfaces and cut valleys had easily formed. The area under the slope break zone normally received sedimentation, and usually formed basin fans and slope fans dominated by coarse clasts. Those types of formations generally correspond to the sedimentary characteristics of low water level system tracts. Under such conditions, the identification of the initial lake flood surfaces can be determined using the interfaces corresponding to the overlapping points under the in-phase axis caused by rising lake levels, as well as the overland migration of the lake shore, which tends to connect the 
relatively independent water bodies together. Therefore, the low stand system tract, transgressive system tract and high stand system tract can be identified within the sequence. This sequence filling model was limited to the SQ7 sequence period in the current study. The sedimentation during that period was mainly composed of alluvial fan, braided river delta, shallow-shore lake, and semi-deep lake sedimentary systems.

The SQ7 sequence period was selected as the object in order to establish a development model of the sequence system tract of gentle slope zones with a slope break zone (Figure 7B). During the development stage of the lake basin, the boundary of the abrupt changes from shallow water facies to deep water was represented by a slope break zone. During the period of the low water level system tract, the fan body-turbidite fans of the alluvial system dominated by coarse clastic had developed in the slope break zone, and both disorganized reflection and mound reflection were dominant in the seismic profile. The characteristics of the denudation zone appeared above the slope break zone, and the main features below the slope break zone were cut valleys and denudation surfaces. Furthermore, during the lacustrine transgression system tract period, a large set of dark pure mudstone was deposited under the action of rapid transgression, which was a lacustrine deposit. During the period of the high-water system tract, large-scaled braided river delta deposits had developed, and the slope break zone had major influencing effects on the distributions of the braided river delta front zones and depositional centers.

This study found that from the SQ1 sequence period to the SQ7 sequence period, the Nanpu No. 3 structure had undergone longterm uplifts and denudation since the Cambrian Period. The study area received proximal sediment deposits from the Shaleitian Salient in the southwestern direction during the 3rd and 2nd stages of the Shahejie Formation, forming the SQ1 and SQ2 sequences. These were mainly fan deltaic and lacustrine sedimentary systems, which were characterized with large thicknesses and secondary stratification sequences of a lacustrine regressive system tract and a transgressive system tract. Subsequently, local tectonic uplifts occurred in the Nanpu No. 3 structural area. In the first section of Shahejie Formation, the grain sizes of the sediment from the Shaleitian Salient became finer, and the sorting and grinding became better. Then, according to the large-scaled water transgression and regression periods, the SQ3 and SQ4 sequences were formed. These sequences mainly included braided river delta-lacustrine facies with small thicknesses, as well as a secondary stratification sequence of a lacustrine regressive system tract and a transgressive system tract. Following the formation of the Shahejie Formation, the study area suffered strong tectonic activities and large-scaled denudation. During the eastern third section period, the study area showed retrogradation overall and the scope of the lake basin expanded. Then, according to the transgression and regression periods, as well as the distributions of the sediment, the SQ5 and SQ6 sequences were formed, which mainly included braided river delta-lacustrine facies with medium thicknesses, and secondary stratification sequences of a lacustrine regressive system tract and a transgressive system tract. In the second section of the Dongying Formation, a structural slope break zone was formed in the area of the NP3-27 well due to local uplifts in the structure. Then, after the sediment from the southwest had crossed the slope break zone, the SQ7 deposits were formed. These consisted of a low stand system tract dominated by fan bodies and turbidite; a lacustrine transgressive system tract dominated by shallow-shore lakes and fairly deep lakes; and a high-stand system tract dominated by braided river delta fronts.

\section{CONCLUSION}

1) The material sources of the Nanpu No. 3 structural area were determined to have originated from the southwest Shaleitian Salient. In the middle and deep strata, fan delta deposits, braided river delta deposits, shallow-shore lake deposits, and deep-water slump turbidite fan deposits were mainly developed. In the SQ1 and SQ2 sequences, a fan delta and shallow-shore lake depositional system was mainly developed. Then, from the SQ3 sequence to SQ7 sequence, a braided river delta-shallow-shore lake/turbidite depositional system with multi-stage superimposition was developed. The distribution range was obviously controlled by the tectonic setting of the gentle slope zones within the lake basin. There was also a set of braided river delta deposits formed by the braided river system directly entering the lake basin in the shallowshore lake areas.

2) Two types of sequence filling models were established in this study by taking the Nanpu No. 3 structural area as the prototype. These included a sequence filling model without a slope break zone and a sequence filling model with a slope break zone. The sequence depositional model without a slope break zone was the main sequence filling model for the study area. It included the development of a lacustrine transgressive system tract and a lacustrine regressive system tract. The sequence depositional model with a slope break zone appeared only in the SQ7 sequence, with the development of a low-stand system tract, lacustrine transgressive system tract, and a high-stand system tract. During the Paleogene Period, three tectonic uplifting activities occurred in the Nanpu No. 3 structural area, and three large-scaled water transgression and regression periods occurred. The area had continuously received sediment from the southwestern direction, forming the present day SQ1 to SQ7 sedimentary patterns.

\section{DATA AVAILABILITY STATEMENT}

The original contributions presented in the study are included in the article/supplementary material, further inquiries can be directed to the corresponding author.

\section{AUTHOR CONTRIBUTIONS}

HZ, ZL was mainly responsible for the conception of the article. They put forward a good idea and completed the research content related to sedimentary facies and evolution characteristics in the article. $\mathrm{XL}, \mathrm{XH}$ wrote sections of the 
manuscript. All authors contributed to manuscript revision, read, and approved the submitted version.

\section{ACKNOWLEDGMENTS}

We greatly thank China University of Petroleum (East China) and Exploration and Development Research Institute of PetroChina

\section{REFERENCES}

Dong, Y. X., Yang, S., Chen, L., Wang, Q., and Cao, Z. H. (2014). Braided River Delta Deposition and Deep Reservoirs in the Bohai Bay Basin: A Case Study of the Paleogene Sha 1 Member in the Southern Area of Nanpu Sag. Pet. Exploration Dev. 41 (4), 429-436 [in Chinese with English Abstract]. doi:10.1016/s1876-3804(14)60049-5

Fan, B. J., Liu, C. L., Liu, G. D., and Zhu, J. (2010). Forming Mechanism of the Fault System and Structural Evolution History of Nanpu Sag. J. Xi'an Shi you University (Natural Sci. Edition) 25 (2), 13-17 [in Chinese with English Abstract]. doi:10.3969/j.issn.1673-064X.2010.02.003

Feng, Y. L., Zhou, H. M., Ren, J. Y., Zheng, H. R., and Miao, S. D. (2010). Paleogene Sequence Stratigraphy in the East of the Bohai Bay Basin and its Response to Structural Movement. Sci. Sin Terrae 40 (10), 1356-1376 [in Chinese with English Abstract]. doi:10.3724/SP.J.1011.2010.01081

Huang, M. N., Dong, Y. X., Pang, X. Q., Hao, H. J., and Guo, J. G. (2012). Controlling Factors of Structural Reservoir Distribution and its Prediction Method in Nanpu depressionBohai Bay Basin. Oil Gas Geol. 33 (05), 695-704 [in Chinese with English Abstract]. doi:10.11743/ogg20120505

Jiang, F. J., Dong, Y. X., Pang, X. Q., Wang, Y. X., Guo, J. G., and Fan, B. J. (2013). Hydrocarbon Distribution Features and Main Controlling Factors in the Nanpu Sag. Geoscience 27 (05), 1258-1264 [in Chinese with English Abstract]. doi:10.3969/j.issn.1000-8527.2013.05.031

Jiang, F. J., Pang, X. Q., Li, L., Wang, Q. C., Dong, Y. X., et al. (2018). Petroleum Resources in the Nanpu Sag, Bohai Bay Basin, Eastern China. AAPG Bulletin 102 (7), 1213-1237. doi:10.1306/0906171608017148

Jiang, H., Wang, H., Lin, Z. L., Fang, X. X., Zhao, S. E., and Ren, G. Y. (2009). Periodic Rifting Activity and its Controlling on Sedimentary Filling of Paleogene Periodin Nanpu Sag. Acta sedimentologica Sinica 27 (05), 976-982 [in Chinese with English Abstract]. doi:10.14027/j.cnki.cjxb.2009.05.022

Jiao, Y. Q., Zhou, H. M., Zhuang, X. G., Liu, S. F., Yang, S. K., and Ma, M. Y. (1998). Fan Deltaic Depositional Systems and Their Relationship to Oil and Gas Accumulation. Acta sedimentologica Sinica 16 (01), 70-75 [in Chinese with English Abstract]. doi:10.14027/j.cnki.cjxb.1998.01.012

Li, H., Zhang, H. Y., Xu, Y. X., Wang, Y. L., Zhao, Q., and Wang, K. (2018). Sedimentary Characteristics and Genetic of the Lower Ed3 Formation Fluxoturbidite in the East of Nanpu Structure 5. Oil Geophys. Prospecting 53 (S2), 321-328 [in Chinese with English Abstract]. doi:10.13810/ j.cnki.issn.1000-7210.2018.s2.050

Li, S. T., Wang, D. Y., Wang, B., Tao, H. F., and Liu, Z. W. (2008). Identification of Sedimentary Slope Breaks in the Margin of a Down Warped Lake Basin's Ramp Belt: A Case from Triassic Yanchang Formation'Ordos Basin. Nat. Gas Geosci. 19 (1), 83-88 [in Chinese with English Abstract].

Li, S. Z., Suo, Y. H., Zhou, L. H., Dai, L. M., Zhou, J. T., Zhao, F. M., et al. (2011). Pull-Apart Basins within the North China Craton: Structural Pattern and Evolution of Huanghua Depression in Bohai Bay Basin. J. Jilin $U$ University(Earth Sci. Edition) 41 (05), 1362-1379 [in Chinese with English Abstract]. doi:10.13278/j.cnki.jjuese.2011.05.041

Li, X. B., Liu, H. Q., Chen, Q. L., Wan, Y. R., Wei, L. H., Feng, M., et al. (2010). Characteristics of Slope Break Belt in Large Depression Lacustrine Basin and its Controlling Effect on Sandbody and Petroleum. Acta sedimentologica Sinica 28 (04), 717-729 [in Chinese with English Abstract]. doi:10.14027/ j.cnki.cjxb.2010.04.016

Lin, C. S., Pan, Y. L., Xiao, J. X., Kong, F. X., and Liu, J. Y. (2000). Structural Slope-Break Zone: Key Concept for Stratigraphic Sequence Analysis and Petroleum Forecasting in Fault Subsidence Basins. Earth Sci. 25 (30),
Jidong Oilfield Branch for providing all the related core samples, geological data and permission to publish these data. This study supported by the state key scientific project "The central government guided local science and technology development special project (Shandong Unconventional Hydrocarbon Resources technology innovation platform)". We thank our scientific research team for their help and guidance in the field investigation.

260-265 [in Chinese with English Abstract]. doi:10.3969/j.issn.16715888.2011.05.010

Liu, L., Zhong, Y. J., Chen, D. H., and Wang, J. (2015). Contrastive Research of Fan Deltas and Braided River Deltas in Half-Graben Rift Lake Basin in East China. Acta sedimentologica Sinica 33 (06), 1170-1181 [in Chinese with English Abstract]. doi:10.14027/j.cnki.cjxb.2015.06.010

Liu, X., Liu, Z., Lu, C. J., Ren, M. Y., Li, L., Wang, S. L., et al. (2017). Evolution of Sedimentary Source and Controlling Factors of sandstone Body Distribution in the Middle-Upper Part of the Third Member of Shahejie Formation in Liuzan area, Nanpu Depression. Acta Petrolei Sinica 38 (8), 888-901 [in Chinese with English Abstract]. doi:10.7623/syxb201708004

Liu, Y. L., Qiu, C. G., Deng, H. W., and Li, M. (2008). Control of the Structure of the Paleogene Dongying Formation upon Fan-Deltadeposition in the Nanpu Depression Jidong Oilfield. Oil \& Gasgeology 29 (01), 95-101 [in Chinese with English Abstract]. doi:10.11743/ogg20080115

Lv, D. W., Song, Y., Shi, L. Q., Wang, Z. L., Cong, P. Z., and T van Loon, A. J. (2020). The Complex Transgression and Regression History of the Northern Margin of the Palaeogene Tarim Sea (NW China), and Implications for Potential Hydrocarbon Occurrences. Mar. Pet. Geology. 112. doi:10.1016/j.marpetgeo.2019.104041

Lv, D., Li, Z. X., Wang, D. D., Li, Y., Liu, H. Y., Liu, Y., et al. (2019). Sedimentary Model of Coal and Shale in the Paleogene Lijiaya Formation of the Huangxian Basin: Insight from Petrological and Geochemical Characteristics of Coal and Shale. Energy Fuels 33 (11), 10442-10456. doi:10.1021/ acs.energyfuels.9b01299

Qi, P., Ren, J. Y., Lu, G. C., Shi, S. S., Tong, D. J., and Zhang, J. X. (2010). Cenozoic Episodic Subsidence in the Middle and North Part of Huanghua Depression, Bohai Bay Basin. Earth Sci. - J. China Univ. of Geosciences 35 (6), 1041-1052 [in Chinese with English Abstract]. doi:10.3799/dqkx.2010.118

Ren, J. Y., Liao, Q. J., Lu, G. C., Fu, L. X., Zhou, J. Y., Qi, P., et al. (2010) Deformation Framework and Evolution of the Huanghua Depression, Bohai Gulf. Geotecton. Metallog. 34 (4), 461-472. doi:10.16539/ j.ddgzyckx.2010.04.006

Ren, J. Y., Lu, Y. C., and Zhang, Q. L. (2004). Forming Mechanism of Structural Slope-Break and its Control on Sequence Style in Faulted Basin. Earth Sci. - J. China Univ. Geosciences 29 (5), 596-602 [in Chinese with English Abstract]. doi:10.3799/dqkx.2010.118

Sun, P. K., Jia, L. B., Zhu, H. Z., Zhang, L., He, T. H., Xu, Z. H., et al. (2021). Sequence Architecture and Sedimentary Filling Characteristics of the MiddleUpper Part of the Es3 Formation in the Liuzan Area, Nanpu Depression. Pet. Sci. Bull. 01, 16-30 [in Chinese with English Abstract]. doi:10.3969/j.issn.20961693.2021.01.002

Wang, E. Z., Liu, G. Y., Pang, X. Q., Wu, Z. Y., Li, C. R., Bai, H., et al. (2020). Sedimentology, Diagenetic Evolution, and Sweet Spot Prediction of Tight sandstone Reservoirs: A Case Study of the Third Member of the Upper Paleogene Shahejie Formation, Nanpu Sag, Bohai Bay Basin, China. J. Pet. Sci. Eng. 186, 1-10. doi:10.1016/j.petrol.2019.106718

Wang, J. W., Du, J. X., Zhang, Y. C., Wang, Q. L., and Zhao, S. E. (2019). The Geological Conditions, Resource Potential and Exploration Direction in Nanpu Sag of Jidong Depression. Bohai Bay Basin 24 (3), 21-28 [in Chinese with English Abstract]. doi:10.3969/j.issn.1672-9854.2019.03.003

Wang, Y. M., Liu, H., Li, L. C., Qi, X. F., and Wang, Y. (2002). Types and Distribution Characteristics of Slope Breaks of Large-type Down-Warped Lake Basins. Earth Sci. 27 (6), 683-687 [in Chinese with English Abstract]. doi:10.1007/s11769-002-0045-5

Wu, H., Ji, Y. L., Zhou, Y., Meng, L. J., Zhang, Y. Z., Wu, H., et al. (2019). Origin of the Paleogene Deep Burial High-Quality Reservoirs in the Southern Nanpu Sag. 
J. China Univ. Mining Technolog 48 (3), 553-569 [in Chinese with English Abstract]. doi:10.13247/j.cnki.jcumt.000952

Xian, B. Z., Wan, J. F., Jiang, Z. X., Zhang, J. G., Li, Z. P., and She, Y. Q. (2012). Sedimentary Characteristics and Model of Gravity Flow Deposition in the Depressed belt of Rift Lacustrine basin: A Case Study from Dongying Formation in Nanpu Depression. Earth Sci. Front. 19 (1), 121-135 [in Chinese with English Abstract].

Xu, A. N., Zheng, H. J., Dong, Y. X., Wang, Z. C., Yin, J. F., and Yan, W. P. (2006). Sequence Stratigraphic Framework and Sedimentary Facies Preiction in Dongying Formation of Nanpu Sag. Pet. Exploration Dev. 33 (4), 437-443 [in Chinese with English Abstract].

Xu, C. G. (2006). Genetic Types of Paleogene Slope-Break Zones and Their Controls on Depositional System in Bohai Offshore. China Offshore Oil and Gas 18 (06), 365-371 [in Chinese with English Abstract]. doi:10.3969/ j.issn.1673-1506.2006.06.002

Zhang, C. M., and Liu, X. F. (2012). The Boundary Faults and basin Formation Mechanism of Nanpu Sag. Acta Petrolel Sinica 33 (4), 581-587 [in Chinese with English Abstract]. doi:10.7623/syxb201204006

Zhang, C. M., Zhu, R., Yin, T. J., and Yin, Y. S. (2015). Advances in Fan Deltaic Sedimentology, Xinjiang Pet. Geology. 36(03), 362-368 [in Chinese with English Abstract]. doi:10.7657/XJPG20150323
Zhou, Y. H., Yang, S. C., Feng, J. W., Lan, Z. Q., and Zhang, B. M. (2016) Characteristics of fault activities and the controlling on sand bodies during Es1 period in Nanpu No.3 unit. Journal of Northeast Petroleum University. 40 (02), 27-35 (in Chinese with English Abstract). doi:10.3969/j.issn.2095-4107.2016.02.004

Zhou, H. M., Wang, Z. C., and Guo, Y. H. (2000). Tectonic Controls on Sequence Stratigraphy in Tertiary Period in Nanbao Depression. J. China Univ. Mining Tech nology 29 (03), 104-108 [in Chinese with English Abstract]. doi:10.3321/ j.issn:1000-1964.2000.03.025

Conflict of Interest: The authors declare that the research was conducted in the absence of any commercial or financial relationships that could be construed as a potential conflict of interest.

Copyright (ㄷ) 2021 Zhang, Lan, Li and Huang. This is an open-access article distributed under the terms of the Creative Commons Attribution License (CC $B Y)$. The use, distribution or reproduction in other forums is permitted, provided the original author(s) and the copyright owner(s) are credited and that the original publication in this journal is cited, in accordance with accepted academic practice. No use, distribution or reproduction is permitted which does not comply with these terms. 